Journal of Business and Tourism

Volume 04 Number 02

July-December, 2018

\title{
Learning English as a Second Language: Orientations Among the Undergraduate Students of Business Administration in Southern Punjab
}

\author{
UZMA SADIQ \\ Assistant Professor, University of Education, DG Khan Campus \\ uzmasadiq@yahoo.com \\ NAZIA SULEMAN \\ Assistant Professor, COMSATS University Islamabad, Vehari Campus \\ naziasuleman@ciitvehari.edu.pk \\ MUHAMMAD ZAHID NAWAZ \\ COMSATS University Islamabad, Vehari Campus \\ IRAM GUL \\ COMSATS University Islamabad, Vehari Campus
}

\begin{abstract}
The motivation to learn English as a second language is always motivated through different orientations which are of ultimate interest to the researchers. These orientations are originating from both integrative as well as instrumental conceptualizations. As the lingua franca is English so these orientations are becoming more complex. In Pakistan, where English is used as L2 new orientations are emerging with the growing needs. The factor analysis employed by Mansoor (2015) in KhyberPakhtunkhwa is taken as a model framework to study the same in Southern Punjab (Pakistan). For the current study a sample of 150 students of Business Administration Department of universities at Southern Punjab were taken as a population for the factor analysis. The findings support the fact that the integrative factor which is 'Matter of Dignity' towards studying English as a second language from the available set of orientations is a stronger factor among the undergraduate students of Southern Punjab.
\end{abstract}

Keywords: L2, Orientations, Motivation, English, Factor

\section{Introduction}

English is used for the purpose of communication in all the universities of Pakistan. English is not only the language of books but is also used for communication purposes inside and outside the classroom. The people are also connected with the educated community via social media around the globe (Islam, 2013). Motivation is always categorized as one of the key factor for second language learning. The paper tried to investigate the needs, drives and desires which make the learners learn a foreign language and all these are comprehensively labeled by Gardner and Lambert (1959) as orientations. These orientations are the focus of this research study which are not fixed rather it varies from country to country and here we are probing those orientations which 
are making Pakistani L12 learners learn the English language. Although a good number of research has been done on L2 and its orientations by Gardner and Lambert $(1959,1972)$ yet there is much more to explore on these orientations. These orientations do vary depending on the culture, linguistic and learner's factors and are complex too as mentioned in Bradford, (2007). The orientations for L2 learning are many but here the focus is on the orientations for learning English in particular.

\subsection{Research Question}

The research answers the following research question:

Q. What are the significant L2 factors among the undergraduate students of business administration towards learning English as a second language in South Punjab?

\section{Review of Literature}

Gardner \& Lambert (1959), conducted their research work on L2 motivation which has a very good impact upon the fellow researchers, these were the persons who worked on the involvement of integrative and instrumental roles in L2 and its learning. In Pakistan, young people are more inclined towards learning English for the growth and development as it is considered a gateway towards development and success (Shamim,2011). English always remained a prestigious language in the country and is considered more powerful than Urdu (Mansoor, 20115; Rahman, 2002 ; Shamim,2011). Shahbaz and Liu (2012) did their research about the L2 orientations and the themes concerning the motivation to learn a language. Gardner and Lambert (1959) both had a considerable contribution in identifying the significance of instrumental and integrative orientations which helps in influencing L2 and it also encouraged many other fellow researchers to probe down the area. For the L2 motivation there are multiple expression in use like desire to learn English and the motivations to learn L2. In addition, at times it is mixed with the attitudes and the motivations towards L2. L2 orientations are comprised of the reasons to learn L2 within the context of motivation. Shamim (2011) has categorized the English language as a gateway not only to success but also to knowledge, English always remained a language of power and prestige in Pakistan and is also considered to be the language residing among the group of elites.

\section{Methodology}

An exploratory factor analysis was conducted on L2 business students of South Punjab in order to find an answer to the research question. In this study, a pilot study was initially conducted at Vehari where the motivation to learn the English language were figured out among the business students after a small survey. A questionnaire consisting of 15 items was designed to collect data from the respondents. 10:1 was the ratio of research items to participants which is considered fine for the study (Spicer,2005). The sample comprising of 150 students of Business Administration (males, females) from COMSATS University Islamabad, Vehari Campus filled out a questionnaire. All the respondents were in their BS study and in the mid of their degree and studied English as a compulsory subject in four semesters.

SPSS (Statistical Package for the Social Sciences) was used to analyze the quantitative data. We have used the factor analysis to find out the interrelationships among items. The set of data analytical tools was employed for the factorability of data like KMO, principal component approach, Kaiser's criterion, scree plot for variance and Orthogonal Varimax approach for the rotation of factor. Through the factor analysis we have explored those 
components which are most powerful. These powerful components compelled the learners to learn English as a second language. The theoretical framework for the current study is derived from Mansoor (2015) who did his work on the English language and its motivational factors.

\section{Analysis}

Firstly, we have used Kaiser-Meyer-Olkin (KMO) to check the factorability of the data and to measure sampling adequacy and Bartlett's test of sphericity (Cohen and Morrison, 2011). The KMO and Bartlett's test of sphericity values are .716 and .000 respectively that show that the data is suitable for factor analysis. The Kaiser-Meyer-Olkin (KMO) values fall between $(-1,0,+1)$ and the value that is close to 1 is considered more appropriate and provide more reliable information during the time of factor analysis. We have applied Principle components approach to reduce the huge number of items into non-correlated that are called factors. We have found $60.41 \%$ total variance of 5 retained factors. Furthermore, according to Tabchnick and Fidell (2013), those items that have more than 0.40 value in the rotated components matrix are considered to be most appropriate.

Secondly, we have used two test Kaiser's criterion and a scree plot which help to identify that which powerful factors have been retained during the extraction process of the factor analysis. The eigenvalue of Kasier's criterion is based on 1.0, which depicts the amount of total variance by each factor. The main purpose to use Kasier's criterion is to indicate those retain factor which has more than one (>1.0) eigenvalue

Table 1: KMO and Bartlett's Test

\begin{tabular}{ccc}
\hline \multicolumn{3}{c}{ KMO and Bartlett's Test } \\
\hline Kaiser-Meyer-Olkin Measure of Sampling Adequacy. & .716 \\
& Approx. Chi-Square & 475.661 \\
Bartlett's Test of & Df & 105 \\
Sphericity & Sig. & .000 \\
\hline
\end{tabular}

Table 2: The eigenvalues and variance for each of the 5 retained factors.

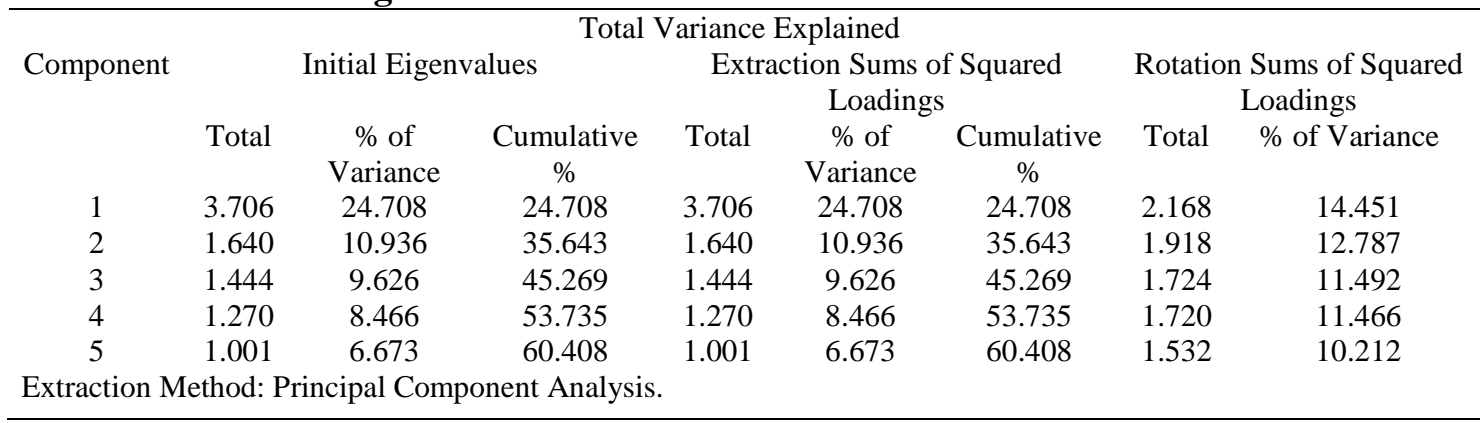

Furthermore, we have used Scree plot, which depicts an "inflection" after the 5 retained factors. There are not any hard and fast rules about considering the numbers of factors on the basis of inflection. But we have chosen the component 5 and considered the inflection on it that is showing the greatest result for explaining many orientations. 


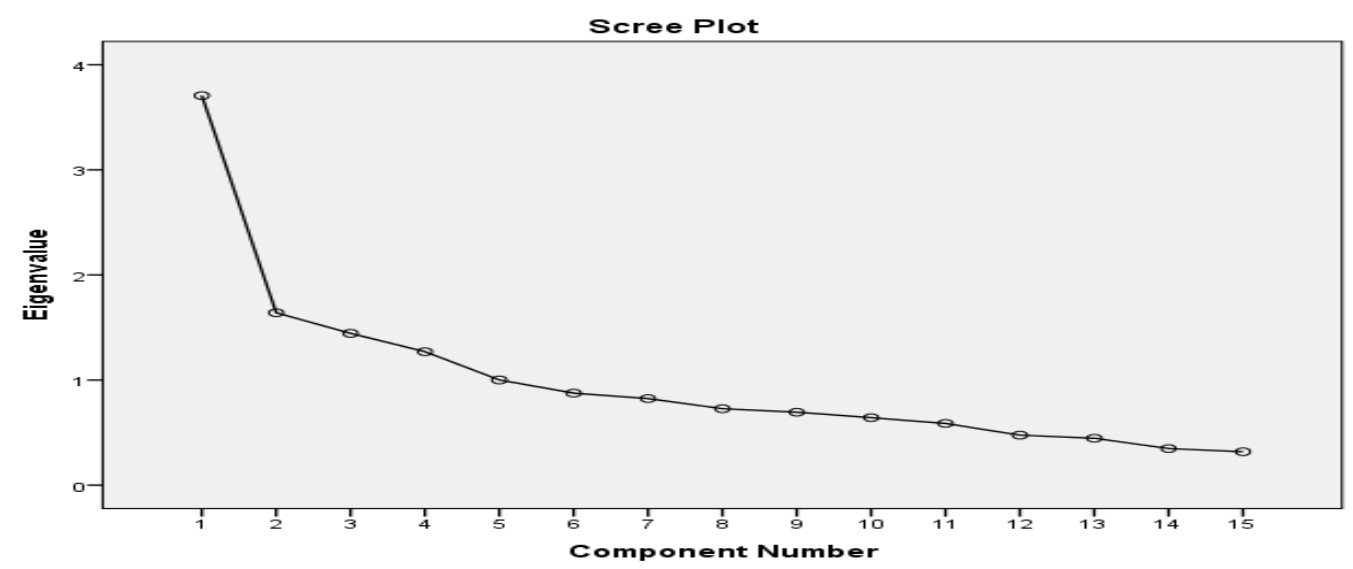

Figure 1: Scree plot of L2 motivational orientations

Thirdly, we have selected the orthogonal Varimax approach during the rotation of the factor analysis, which helped us to analyze the 5 factors. Varimax approach is normally used to rotate the initial factor matrix (Tabachnick and Fidell, 2013). Through the use of Varimax approach we can easily minimize the number of unrelated items that are loadings on multiple factors. Furthermore, we have used the Varimax approach that helps us to redistribute the data between the factors in order to simplify the interpretation (Harman, 1976). In fact, this Varimax Rotation analysis provided a very clear factor structure with 5 factors that receives loading differently on the 15 items (Table 3). To ensure a strong and stable component, the retained items that have minimum loadings of 0.40 is considered admissible (Dornyei, 1990 and Bradford, 2007). The results given below in the table 3 are of the Rotated Component Matrix

Table 3 : Rotated component matrix

Rotated Component Matrix ${ }^{\mathrm{a}}$

\begin{tabular}{l|l|l|l|l|l|c}
\hline \multirow{2}{*}{ Questionnaire items } & \multicolumn{5}{|c}{ Component } \\
\cline { 2 - 6 } & 1 & 2 & 3 & 4 & 5 \\
\hline
\end{tabular}

q 11. I want to learn English language to gain respect

.803

q 10. I enjoy the feelings when I speak in English language .758

q 12. I want to learn English language because of the university policy

q 15. I want to learn English language to watch TV channels in English language

q 14. I want to learn English language to take an examination such as IELTS

q 6. I want to learn English language to understand English movies 
q 2. I want to learn English language to travel in other countries

q 5. I want to learn English language to study in a foreign country

q 3. I want to learn English language to read English newspaper

q 7. I want to learn English language to earn money

q 1. I want to learn English language to get a job

q 9. I want to learn English language to understand Pakistani political talk shows which are in English language

q 4. I want to learn English language to be successful in business

q 8. I want to learn English language to join international organization

q 13. I want to learn English language because I want to continue studies at higher education level

Extraction Method: Principal Component Analysis.

Rotation Method: Varimax with Kaiser Normalization.

a. Rotation converged in 7 iterations.

\subsection{Labeling of Factors}

\subsubsection{L2 as Matter of Dignity}

Factor 1 is labelled as 'L2 matter of dignity have highly loadings on items $(11,10,12)$ suggest that the respondents have desired to learn English language in order to become a well-respected member of our community. As items 11 (I am learning English language for respect), 10 (I enjoy speaking the English language), and 12 (university policy asks us to learn the English language) clearly indicate that the English language is learnt in Pakistan for the purpose of dignity. This factor is similar in many respects to Bradford's (2007) 'L2 matter of dignity', with item 11 similarly highly loaded. In addition, it is a myth that the English language is spoken by those people who have high status and ranks in the society. Moreover, Mansoor (2015) has stated that the people who have fluency in speaking English language are appreciably considered the most respected members of community. So, according to him, L2 competence in the English language is normally considered a level of respect for the people of Pakistan, and it is also recognized a gateway to prestige in Pakistan. However, L2 Prestige is considered an appropriate label due to the highly loadings of item 11.

\subsubsection{L2 and Interaction on Social Media}

Factor 2 receives strong loadings from items 15 (I want to learn English language to watch TV channels in English language), 14 (I want to learn English language for 
international examination) and 6 (I want to learn English language to get an understanding of English movies) is labelled 'L2 interaction on social media'. These items are extremely similar to, but slightly more homogenous than the English media use orientations defined by McCelland (2000) in his work of Japanese students. Mansoor (2015) have shared similar orientations in his studies. Furthermore, the appreciable loadings of 15 and 6 items on this component may depict the increasing popularity of satellite television and international cable. As Saraceni (2010) highlighted that English television channels like Al Jazeera are equally famous even in Pakistan and elsewhere. Moreover, we cannot deny the use of the English language in the electronic and print media, because the English language is flourishing rapidly as a medium of information and communication. In addition, according to Islam (2013) the use of L2 in media channels are developing rapidly within the country. However, L2 Media is considered as an appropriate label due to the powerful loadings of variable 15.

\subsubsection{L2 for Travelling and to Study Abroad}

Factor 3, is a binary factor that is labeled 'L2 for Travelling and Abroad Study due to the appreciable loading of items (2, 5 and 3$)$. Factor 3 is particularly separated into two major themes; items 2 (I want to learn English language to travel in other countries) relevant to travel and 5 (I want to learn English language to study in a foreign country) and 3 (I want to learn English language to read English newspaper) that are similar with further study, that utilitarian aims to learn the English for study purposes. Moreover, the high loading of item 5 has defined similar orientation in his study of Bradford (2007). According to Saraceni (2010), many English non-native learners have desired to study in the foreign country such as British, American and Australian. However, component 3 also shares some utilitarian similarities with 'L2 Travel-Friendship' of Mansoor (2015).

Meanwhile, the loading of two 'L2 Abroad Study-Travel' orientations together on factor 3 may have utilitarian significance for Pakistani L2 learners. As Shahbaz and Liu (2012) stated that Pakistan is becoming rapidly more affluent region in the Middle East that is supplying skillful persons. However, L2 Abroad Study-Travel is considered a suitable label due to the strong loadings of items 2 and 5.

\subsubsection{L2 for Success -Employment}

Factor 4 is thus another binary factor, labelled 'L2 for Employment-Success 'due to the highest loading of focused items $(7,1,9,4)$. The first orientation here is mainly 'L2 Employment' which include items 7 (I want to learn English language for earning purposes) and (I want to learn English language for hunting job). The loading of these items on factor 4 showing 'employment' purpose for L2 learning, that is also identified by Lamb (2004), Waseem and Jibeen (2013), Pathan et al. (2010). According to Shahbaz and Liu, (2012), English as a second language in Pakistan is playing an indispensable role and it is also considered an important gateway to find any job and employment. Meanwhile, it is clear that most of the L2 learner have desired to learn English language for the sake of job. Furthermore, the 'L2 Employment' has shared some appreciable similarities with 'L2 Travel-Friendship' of Mansoor (2015).

Moreover, the second orientation is here 'L2 Success' that deals with items 4 (I want to learn English language to be successful in business) and 9 (I want to learn English language to get an up to dated knowledge of the Pakistani political talk shows). However, the first appreciable loaded item is adequate to indicate the meaning of this business 
orientation, the second (9) is less clear cut. Interestingly according to Bradford (2007) the second item is considered in the context of cross loading. She also argues that it is similar to "self-perception of success and achievements", although the first item is highly concentrating to her "success" orientation. Our 'L2 Success' has some familiarities with 'L2 instrumental' of Dornyei (1990) and 'L2 career (instrumental)' of Hammel's and Belmechri (1998) is taken as the first (4) business item that is loaded on each.

Meanwhile, the loading of two 'L2 Employment-Success' orientations together on factor 4 may have utilitarian significance for Pakistani L2 learners. As Shahbaz and Liu (2012) stated that Pakistan is becoming a developed region in the Middle East that is supplying skillful persons. However, 'L2 Employment-Success' is considered as an appropriate label due to the strong loadings of items 7 and 9.

\subsubsection{L2 for Higher Studies}

Factor 5 can easily be labeled as "L2 for Higher studies" as it obtained appreciative loadings (greater than 0.40) from two different variables like, 13 (I want to learn English language for higher studies) and 8 (I want to learn English language to join international organization). These two items that are loading onto factor 5 are clearly relevant with learning English to get knowledge. Furthermore, many L2 respondents have desires to join international organizations that essentially demand that these respondents must have command in the English language, because most of the national or international organizations use English language as a mode of communication. Moreover, most of the learners are eager to learn the English language because they want to get education at higher level. In educational institutions like in our country and in foreign countries English is used as a medium of instruction. It is considered that the higher education is necessary to become proficient in all language skills such as writing, speaking, listening and reading.

\section{Conclusion}

The major purpose of this study was to investigate the levels of motivation among the students of undergraduate level at district Vehari with the help of factor analysis. After doing the factor analysis, we had found five main components and two of them were 'binary' that loaded with two L2 orientation on each. The results of analysis reveal that learners do exhibit a variety of L2 motivational orientation among them the primary is the orientation for dignity and respect in the students of Southern Punjab. Mansoor (2015) found that national interest is one of the main factor of learning English language in KPK whilst in Southern Punjab it is found that learning English is a matter of dignity and respect among the peers. Communication on social media has also attracted the young generation and the influx of social media has totally changed the mode of communication therefore the students in southern Punjab want to equip themselves with the latest trends prevailing in a particular community.

\section{References}

Belmechri, F., \& Hummel, K. (1998). Orientations and motivation in the acquisition of English as a second language among high school students in Quebec City. Language Learning, 48(2).

Bradford, A. (2007). Motivational orientations in under-researched FLL contexts: Findings from Indonesia. RELC Journal, 38(3). 
Clément, R., Dörnyei, Z., \& Noels, K. A. (1994). Motivation, self-confidence, and group cohesion in the foreign language classroom. Language Learning, 44(3).

Cohen, L., Manion, L., \& Morrison, K. (2011). Research methods in education (7th ed.). London: Routledge.

Dörnyei, Z. (1990). Conceptualizing Motivation in Foreign-Language Learning. Language Learning, 40(1).

Dörnyei, Z. (2005). The psychology of the language learner: Individual differences in second language acquisition. London: Routledge.

Gardner, R. C., \& Lambert, W. E. (1959). Motivational Variables in Second-Language Acquisition. Canadian Journal of Psychology, 13(4).

Gardner, R. C., \& Lambert, W. E. (1972). Attitudes and motivation in second language learning. Rowley, Massachusetts: Newbury House Publishers.

Harman, H.H. (1976). Modern factor analysis. Chicago: University of Chicago Press.

Islam, M. (2013). L2 motivational self-system and relational factors affecting the L2 motivation of Pakistani students in the public universities of Central Punjab, Pakistan. Unpublished PhD dissertation. University of Leeds, Leeds. Retrieved from http://etheses.whiterose.ac.uk/5054/

Lamb, M. (2004). Integrative motivation in a globalizing world. System, 32(1), 3-19.

Mansoor, S. (2005). Language planning in higher education. A case study of Pakistan. Karachi: Oxford University Press.

Mansoor, M. Wyatt, D. Laar. (2015) Pakistani postgraduate students' orientation for learning English as a second language: A factor analytical study. System 51.

McClelland, N. (2000). Goal orientations in Japanese college students learning EFL. In S. Cornwell \&. P. Robinson (Eds.), Individual differences in foreign language learning: Effects of aptitude, intelligence, and motivation (pp. 99-115). Tokyo: Japanese Association for Language Teaching.

Ozkut, I. E. (1991). The nature of motivational factors related to achievement of English as a foreign language in Turkey. Unpublished $\mathrm{PhD}$ dissertation. University of Ottawa, Ottawa. Retrieved from http://www.ruor.uottawa.ca/bitstream/10393/7819/1/NN75096.PDF

Pathan, H., Shahriar, A., \& Mari, M. A. (2010). Motivation for learning English in Pakistan. ELF Annual Research Journal, 12.

Rahman, T. (2002). Language, ideology and power. Karachi: Oxford University Press.

Saraceni, M. (2010). The relocation of English: Shifting paradigms in a global era. Basingstoke: Palgrave Macmillan.

Shamim, F., \& Allen, P. (2000). Activity types and pattern of interaction in language classrooms in Pakistan (Unpublished research report). Karachi, Pakistan: Aga Khan University, Institute for Educational Development.

Shahbaz, M., \& Liu, Y. (2012). Complexity of 12 motivation in an Asian ESL setting. Porta Linguarum, 18.

Spicer, J. (2005). Making sense of multivariate data analysis. Thousand Oaks, Calif: Sage Publications.

Tabachnick, B. G., \& Fidell, L. S. (2013). Using multivariate statistics (6th ed.). London: Pearson. 
Waseem, F., \& Jibeen, T. (2013). Anxiety amongst learners of English as a second language: An examination of motivational patterns in the Pakistani context. International Journal of Humanities and Social Science, 3(16). 